\title{
Male-built nest volume varies with colony and the timing of the breeding season but not with the nesting-substrate quality and egg production in whiskered terns
}

\author{
JEAN MARC PAILLISSON ${ }^{1}$ and Rémi Chambon ${ }^{2}$ \\ ${ }^{1}$ Université de Rennes 1 - Campus de Beaulieu \\ ${ }^{2}$ Rennes 1 University
}

April 27, 2021

\begin{abstract}
Nest building can represent an energetically-costly activity for a variety of animal taxa. Besides, the determinants of withinspecies variation in the design of nests, notably with respect to natural and sexual selection, are still poorly known although the situation has been partly remedied recently. Based on an observational study, we examined the influence of nesting conditions (nesting-substrate quality, colony, laying date, and year) on the volume of male-built nests and its potential role as a postmating sexually-selected display in the whiskered tern Chlidonias hybrida, a monogamous species with obligate bi-parental care breeding on unstable aquatic vegetation beds. No relationship was found between the nest volume and the nesting-substrate quality (i.e. nest stability) indicating that the density of white waterlily leaves was large enough when whiskered terns breed. In contrast, building a large nest likely constitutes a selective advantage since nests were larger in less densely populated colonies and for early breeders whatever the year. Since being influenced by nesting conditions, the volume of male-built nests was unlikely to be a sexually selected trait in whiskered terns. The reproductive effort by females (the probability of laying one, two or three eggs, and variation in mean egg volume per clutch) was indeed not correlated with the volume of male-built nests. The fitness consequences of building a large nest are yet to be studied and additional investigations are recommended to better depict the participation of males early during breeding (including notably courtship feeding) and later to chick provisioning.
\end{abstract}

\section{Hosted file}

Paillisson_Chambon_Text.pdf available at https://authorea.com/users/410392/articles/519775male-built-nest-volume-varies-with-colony-and-the-timing-of-the-breeding-season-butnot-with-the-nesting-substrate-quality-and-egg-production-in-whiskered-terns 


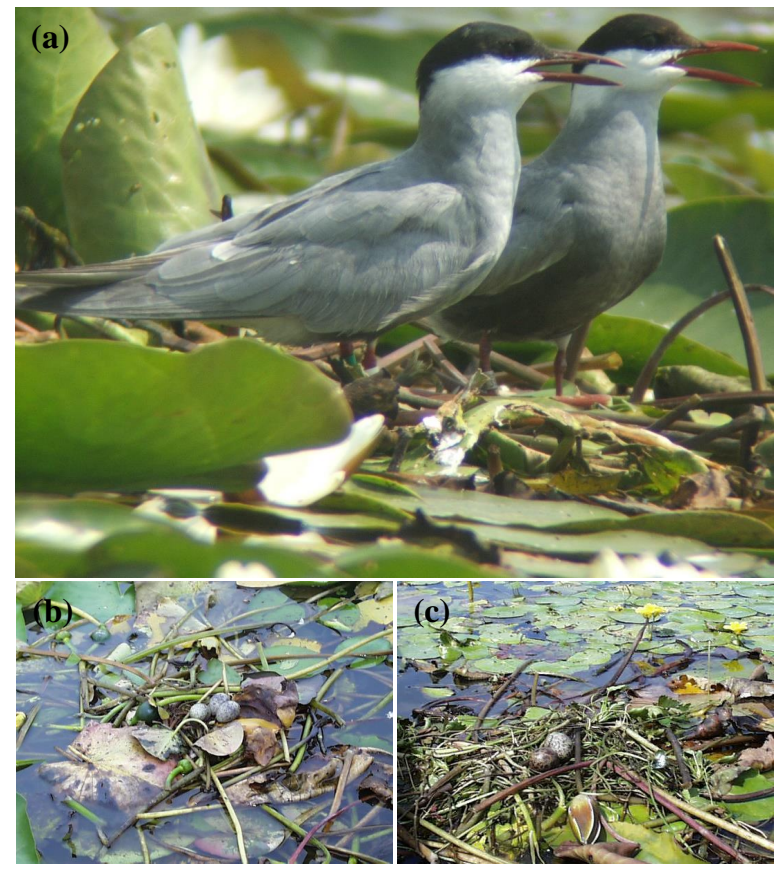



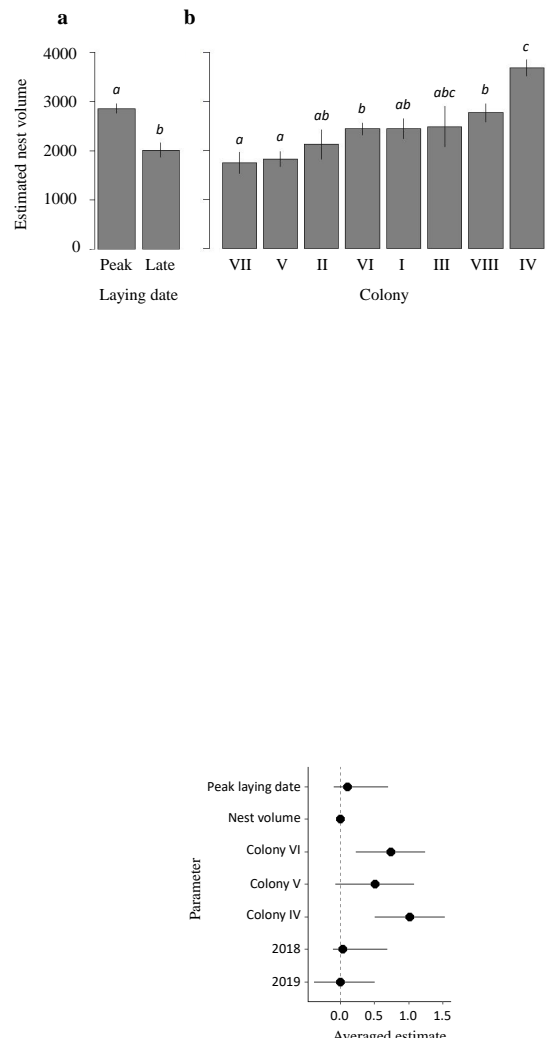